\title{
Measuring meanings of democracy—methods of differentiation
}

\author{
Norma Osterberg-Kaufmann • Ulrich Stadelmaier
}

Received: 14 January 2020 / Revised: 5 October 2020 / Accepted: 17 October 2020 / Published online: 19 November 2020

(C) The Author(s) 2020

\begin{abstract}
The question of the contested nature of the concept of democracy is neither in doubt within the political science debate, nor new. What is new, however, is the attention paid to the knowledge of competing ideas of democracy in literature. The development of concepts of the "D-word" beyond Eurocentric hegemony was accompanied by a critical review of methodological approaches. Against the background of these methodological challenges, the requirements for more differentiated or mixed methodological approaches are discussed in the literature. In this article, a combined approach of the repertory grid and the semantic differential methods is proposed to enrich the innovative methodological dynamics of investigating the meaning of democracy. The article gives an introduction to the repertory grid method and illustrates, with a case study, how the Singaporean middle-class views democracy. These repertory grid face-to-face interviews serve as a starting point for the creation of valid polarity profiles for the semantic differential method-a method which, like the repertory grid, is used to measure the connotative or affective meaning of objects, but in a quantitative design so that representativeness can be achieved. Through this approach, the constructivist approach of repertory grid is partly combined with positivistic survey research, and thus the approach is inductive with deductive research.
\end{abstract}

Electronic supplementary material The online version of this article (https://doi.org/10.1007/ s12286-020-00461-6) contains supplementary material, which is available to authorized users.

Dr. N. Osterberg-Kaufmann $(\bowtie)$

Institut für Sozialwissenschaft, Humboldt-Universität zu Berlin, Unter den Linden 6, 10099 Berlin, Germany

E-Mail: norma.osterberg-kaufmann@hu-berlin.de

Dr. U. Stadelmaier

permitto GmbH, Schöne Aussicht 29, 65193 Wiesbaden, Germany

E-Mail: ulrich.stadelmaier@permitto.com 
Keywords Democracy · Meaning of Democracy $\cdot$ Methods · Repertory Grid · Semantic Differential

\section{Die Messung von Demokratieverständnis - Methoden der Differenzierung}

Zusammenfassung Die Frage nach dem umstrittenen Charakter des Demokratiebegriffs wird in der politikwissenschaftlichen Debatte weder in Zweifel gezogen, noch ist diese Frage neu. Neu ist jedoch die Aufmerksamkeit, die diesem Wissen um konkurrierende Vorstellungen von Demokratie in der Literatur geschenkt wird. Die Entwicklung von Konzepten des „D-Wortes“ jenseits der eurozentrischen Hegemonie wurde von einer kritischen Überprüfung der methodischen Ansätze begleitet. Vor dem Hintergrund dieser methodischen Herausforderungen werden in der Literatur die Anforderungen an differenziertere oder mixed-method Ansätze diskutiert. In diesem Artikel wird ein kombinierter Ansatz aus Repertory Grid und semantischem Differential vorgeschlagen, um die innovative methodologische Dynamik der Untersuchung der Bedeutung von Demokratie zu bereichern. Der Artikel gibt eine Einführung in die Repertory Grid-Methode und veranschaulicht anhand einer Fallstudie, wie die singapurische Mittelschicht die Demokratie wahrnimmt. Diese Repertory Grid-Face-to-Face-Interviews dienen als Ausgangspunkt für die Erstellung gültiger Polaritätsprofile für die semantische Differentialmethode - eine Methode, die wie das Repertory Grid zur Messung der konnotativen oder affektiven Bedeutung von Objekten verwendet wird, jedoch in einem quantitativen Design, so dass Repräsentativität erreicht werden kann. Durch diesen Ansatz wird der konstruktivistische Ansatz des Repertory Grid teilweise mit positivistischer Umfrageforschung und damit induktive mit deduktiver Forschung kombiniert.

Schlüsselwörter Demokratie · Demokratieverständnis · Methoden · Repertory Grid · Semantisches Differential

\section{Introduction}

The question of the contested nature of the concept of democracy is neither in doubt within the political science debate, nor new (Collier et al. 2006). What is new, however, is the amount of attention paid to this question. Indeed, the contested nature of democracy is currently developing into one of the widely discussed research topics of the discipline. As early as 1997, Comparative Democratic Theory, which was initiated by Dallmayr (1997) in political theory, began to foster the idea that "liberal universalism and egalitarianism need to be tempered and corrected through closer attention to cultural heterogeneity and the "politics of difference"" (Dallmayr 1997, p. 282). This is why, Dallmayr (1997) continues, cultural particularities should be taken into account in the conception of democracy.

Since the 2000s, numerous large surveys have been available to study support for democracy worldwide. The results of these surveys have been partially contradictory. During this time, empirical research also began to embrace theoretical considerations 
such as heterogenous meanings of democracy. Since then, the extent to which the results of survey research on democracy should be reinterpreted has also been the subject of debate, due to the existence of patently different views of democracy worldwide.

This prompted leading scholars and leaders of regional public-opinion surveys to focus on how citizens think about democracy and how they weigh democracy against other forms of government. A key finding of one of the first empirical studies on how people view democracy was that people understand democracy differently or are confused about what democracy actually is (Diamond and Plattner 2008). The idea that there is a correct (universal) understanding of democracy is still implicit in the above studies. However, recent literature affirms that democracy is a controversial concept (Canache et al. 2001; Dalton et al. 2008; Welzel and Inglehart 2008; Cho 2015; Schubert 2016; Gagnon 2018), with some literature arguing that the term democracy can be used in different contexts for different purposes.

The evolution of the concepts of the D-word (Bratton 2010) from universalistic hegemony towards the recognition of differences between the concepts was accompanied by a critical review of the methodological approaches used to study democracy. Given these methodological challenges, literature discusses the requirements of more differentiated approaches or respectively mixed-method approaches (Van de Vijver 2003; Rudolph 2005; Pickel 2009; Harkness et al. 2010; Yildiz 2012).

For this reason, an explicit distinction should also be made here between understanding of democracy and meaning of democracy. While the term understanding of democracy means that individually different representations of a still identical object and thus a uniform measurement is still possible, the concept of meanings of democracy permits conceptual ambiguity. Conceptual ambiguity becomes more and more important for science in general, leaving solely linear approaches behind in order to address the volatility, uncertainty, complexity, and ambiguity of today's globalized world. Such approaches have already yielded fruitful alternative explanations in especially organizational and management research (Jarzabkowski et al. 2017; Miron-Spektor et al. 2018; Waldman et al. 2019).

This article will propose a combined approach of the repertory grid method and the semantic differential method to enrich the innovative methodological dynamics of exploring meanings of democracy as a complement to deductive by inductive methods (Schubert 2012, 2016; Cho 2015). The specific advantages of the repertory grid method are that the initial data is qualitative, using the language, words and associations of the respondents, while the analysis uses statistical methods that allow comparison of concepts and meanings. Since the results are directly based on the individual value context of the respondents, problems of equivalence, social desirability and lip service are reduced. The use of the repertory grid therefore enables a completely new approach to transnational and cross-cultural research, new insights in international comparison and a more differentiated understanding of what democracy, for example, means for people. There are clear limits to large-scale faceto-face implementation of the repertory grid. For example, as the methodologically well-structured interviews require time and the associated effort is relatively high compared to standardized surveys, representative samples and thus generalizable results are difficult to garner. The implementation of self-administered online grid 
interviews could be an alternative - although, compared to the questionnaire methodology, participants of the study need much more time to complete the interviews. However, there are currently hardly any systematic studies on the quality and feasibility of self-administered grids (as a rare exception, see Kaulartz and Heckmann 2014) and, as far as the authors know, there is no software that would make this approach practicable. A methodical solution would be an online survey following the personal interviews, which uses the interview results as a means for item development. Through repertory grid face-to-face interviews, valid polarity profiles can be generated to create polarity profiles for semantic differentials-a method like the repertory grid for measuring the connotative or affective meaning of objects, but in a quantitative design, so that representativeness can be achieved (Osgood 2009; Rosenberg and Navarro 2018).

The article aims to contribute to the discussion on the appropriate methodological approach to explore the understanding of abstract concepts such as democracy beyond (Western) normativity. In the context of the question about methodological challenges of democracy research, the article aims to contribute to the inductive/ bottom-up discussion thread. Therefore, the article will reflect the advantages of mixed-method concepts for measuring meanings of democracy under the traveling premise (Schubert and Weiß 2016). In the next chapter, the article will introduce the repertory grid as such a mixed-method and illustrate how the Singaporean middleclass views democracy by outlining the results of a case study. In the final step, the article will present the semantic differential method as a way to integrate the results of the repertory grid interviews as an inductive/bottom-up approach into a deductive/top-down design to enable large $N$-studies and thus representativeness. Through this approach, the constructivist approach of the repertory grid is to some extent combined with positivist survey research.

\section{Methodologically differentiated approaches and mixed-method designs}

Common empirical research on the understanding of democracy is capable of mapping the normative understanding of democracy (deductive/top-down) from the Western perspective, but not to map the heterogeneous meanings of democracy worldwide. Political Theory demands a method with a more innovative and differentiated handling of the question of worldwide meanings of democracy (Yildiz 2012). Discussed as a traveling premise (Schubert and Weiß 2016), Yildiz (2012) put forward the idea of political ideas and terms traveling across cultures. The traveling premise argues that ideas and techniques of governance for example change while traveling over time and space. As ideas and techniques of governance are adapted, they also could include, from a Western perspective, contradictory elements. Comparative Politics should spare no effort to understand those adopted meanings (Yildiz 2012, p. 216). Instead, Comparative Politics follows the misperception of Sartori (1997), who assumed that there should be the one and true core of democracy, which only has to be identified. And if those true values and ideals of democracy have been identified, the Sartori (1997) inspired researcher tends to 
analyze non-Western meanings using prefabricated (Western) criteria. Such an approach leads, following Yildiz's argumentation, to a version of modernization which is Eurocentric and normatively overstated (Dallmayr 2010).

Taking these reflections into account, there are first approaches to differentiate and innovate the methods to understand meanings of democracy worldwide. By combining the ten democracy items of the World Value Survey Wave 2005-2008 ${ }^{1}$, Schubert (2012) tries to identify similarities and differences behind these items. By doing so she identified a core of democracy, consisting of elections, equality, civil rights and referenda, which corresponds to Western meanings. At the same time, she observed differences between countries and inconsistencies about the term democracy amongst non-Western countries, and even entirely new definitions of democracy (Schubert 2012, p. 198). These findings indicate a heterogeneous meaning of democracy with a democratic core following a Western interpretation. Similar findings were also made by Chu and Huang (2010). What is not taken into account in this approach, apart from the common core, is the people's varying views on democracy. Via multidimensional scaling, Schubert (2012) therefore compared the relations of the ten democracy-items in the imaginative spaces of the respondents. Proximities and distances of the items can illustrate similarities and dissimilarities, in this case, typical democratic and undemocratic elements of the definition of democracy. This approach led to the identification of an ideal-typical ${ }^{2}$, a real-typical ${ }^{3}$ and an atypical definition of democracy, which, for example, includes religious leadership in the common core understanding of democracy ${ }^{4}$. The atypical and real-typical definitions included exclusively non-Western countries (Schubert 2012, p. $204 \mathrm{ff}$.) ${ }^{5}$.

Multidimensional scaling is a major advancement to systematize the differences in how people view democracy, but still is bound to disadvantages of survey research, as discussed above. Next steps should be approaches, combining the advantages and potential of quantitative survey research and qualitative methods to overcome pure measurement of normatively defined elements of democracy and to understand the individual evaluation criteria of the respondents themselves. Possible research designs could include multi-level or mixed-methods. While mixed-methods implies different methodological approaches parallel within one study, multi-level integrates them within the respective research phase (Pickel 2009, p. 309).

\footnotetext{
1 V152 Government tax the rich and subsidize the poor, V 153 Religious authorities interpret the laws, V 154 People choose their leaders in free elections, V 155 People receive state aid for unemployment, V 156 The army takes over when government is incompetent, V 157 Civil rights protect people's liberty against oppression, V 158 The economy is prospering, V 159 Criminals are severely punished, V 160 People can change laws in referendums, V 161 Women have the same rights as men (Schubert 2012, p. 194).

2 Consisting of elections, civil rights, equality and referenda, according to the mainstream Western meaning of democracy_opposing the atypical elements (military and religion).

3 The four classical elements of the ideal definition of democracy become combined with socio-economic elements and security. The opposition to the atypical elements remains.

4 The separation of democratic and non-democratic elements has been dissolved.

5 Atypical definition: Indonesia, Egypt, Ghana, Jordan, Iraq; real-typical definition: Romania, Morocco, Mexico, South Africa, Bulgaria, Thailand, China, Zambia, Malaysia, Trinidad and Tobago, Peru, Russia, Japan, South Korea, Moldova, Cyprus and Serbia.
} 


\section{Repertory grid as an alternative approach}

Despite all the innovations within the methodological perspective of political science in the survey of attitudes, for which multidimensional scaling stands as an outstanding example, this perspective nevertheless reaches its limits and therefore we go beyond it in this article and look beyond the disciplinary horizon. Measuring meanings of democracy is in itself a psychological measurement issue, because the researcher wants to explore how individuals think and feel about it, and how those individual perceptions can be aggregated to a generalizable scale, which can be applied to entire populations.

Within the field of psychology, psychometric methods deal with similar questions. As an interdisciplinary approach, therefore, the application of psychometric methods to survey more differentiated meanings of democracy seems promising. Therefore, in the following we briefly introduce the psychometric measurement approach. A socalled item universe will be derived on the basis of the respective subject theory. The item universe defines how the object of interest can be measured with which statements and corresponding participant responses. Once this theoretical item universe is defined, it will be filled with content. This is done by filling the defined statement structure with various evaluable examples of experience and behavior. This process is called item generation. In the course of item generation, at least three times as many items are usually generated than are to be collected later in the final measuring instrument. The reason for this is the so-called scale and item analysis, in which usually only a few items prove to be valid and reliable (Moosbrugger and Kelava 2008; Rost 2004). Throughout these theory-driven steps, the (future) respondents are not involved. As a result, there is a risk that decisive aspects of the perception of the object of measurement might get lost, which also seems to be true for quantitative approaches in political research concerning the limited explanatory power of quantitative survey research (see Introduction). Exclusively theoretical top-down approaches to quantitative measurement of the understanding of democracy appear to lack conceptual depth when generalizing Western concepts to other cultures.

In both policy research and psychometrics, this limitation can be overcome by interviewing people in the target population along the item development steps. This results in a wealth of information, but interpretation, structuring and prioritization is still a purely qualitative judgment of the test developer. Therefore, an exclusively qualitative bottom-up measurement may be conceptually deeper than a theory-based quantitative measurement, but it is much more influenced by uncontrolled factors, comparable to the qualitative approaches discussed in the introductory chapter.

The basic problem for a comprehensive assessment of something to be measured is usually that the researcher tells the respondents what they have to answer (topdown quantitative approach) (Jankowicz 2004). Or, if qualitative extensions are added, there is the risk that the measured object is viewed from a strongly subjective perspective of the researcher (bottom-up qualitative approach).

The repertory grid provides a promising methodological alternative to the usual procedure (Kelly 1955; Walker and Winter 2007), especially when researchers aim at exploring a broader meaning of a concept, i.e. are in search of its differentiation. The repertory grid forms the bridge between qualitative and quantitative methods 
and can be the basis for a mixed-method/multi-level approach, combining qualitative and quantitative tools within one single study and using the data for a subsequent large-scale survey. In this sense, according to Jankowicz (2004), repertory grids can be viewed as a structured interview methodology, combined with a multidimensional rating scale approach.

Repertory grids consist of four aspects (Jankowicz 2004; Shcheglova 2010): The first aspect is the topic. The topic represents (future) interviewees' experiences within the area of interest of the researcher. In the present case, the topic is democracy. The second aspect of the repertory grid is the set of elements. The elements are examples of the topic (e.g. institutions, persons or the like, which are representative of democracy). The third aspect of a repertory grid are the so-called constructs. This term comes from humanistic psychology, which assumes that each person constructs his or her own world through experience. In his/her constructs, his/her construction of reality is reflected. The constructs of the respondents represent the individual constructions of democracy and are therefore at the core of interest. The theoretical pioneers of personal constructs psychology, George A. Kelly, assumed that a construct is always bipolar (Kelly 1955). In a sense, "to the left" can only be understood by the fact that the contrast pole is "to the right". The fourth aspect of a repertory grid is the respondents' quantitative ratings of the elements on their constructs.

One of the well-established methods for conducting a repertory grid interview consists of the following steps. Three elements are presented to the respondent and the respondent is asked which two of them resemble each other and differ at the same time from the third. The interviewee then names how the two elements are similar. This is the first construct pole. The opposite construct pole is determined by asking the interviewees to answer in which manner the third element contrasts with the two similar ones. After the two construct poles have been determined, the respondent conducts a rating of all elements on the construct. This procedure is repeated several times with different element triads. As a rule of thumb, approximately 10 constructs per respondent are revealed. On the one hand, the researcher thereby obtains an extremely profound image of the individual's assessment patterns. On the other hand, the respective ratings create a data structure that can be analyzed using multivariate statistical methods. Table 1 shows a data structure that arose from a single participant's interview.

For a multiple repertory grid, as used in the present study, all participants are asked about the same elements, but the participants contribute their individual constructs to the data structure. The common features behind the individual evaluation patterns can then be analyzed by the usual methods of principal components analysis as well as cluster analysis.

All these substantive advantages are obtained with the considerable practical drawback that repertory grid interviews are extremely complex for the researcher requiring an unreasonable amount of time and resources in large-scale, multinational surveys. Therefore, the authors have decided to use a repertory grid analysis as the basis for a semantic differential, which is based on a methodological solution that builds on the advantages of repertory grid analyses but allows for large samples. 


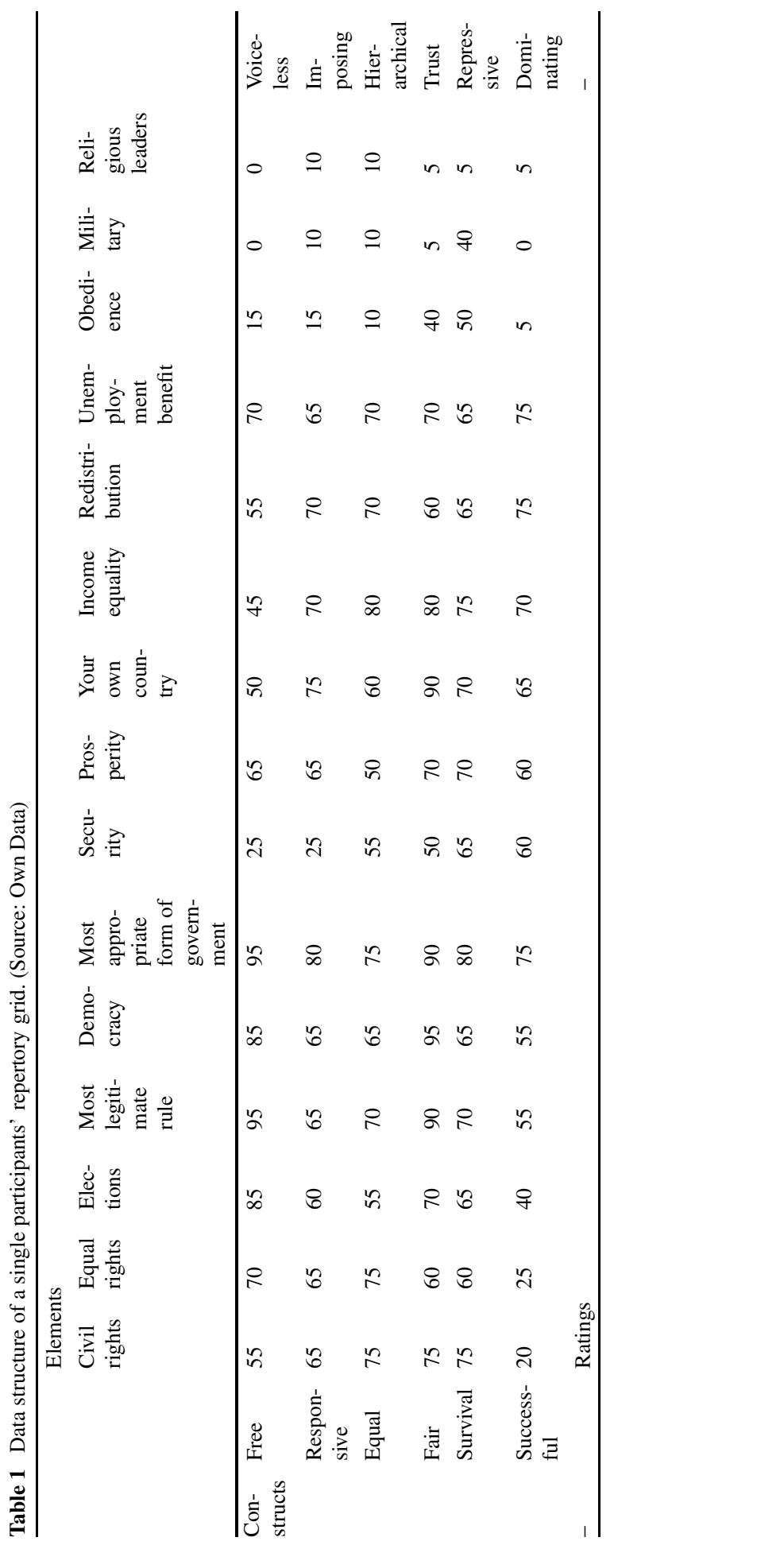




\section{Data analysis and results: How Singaporean middle-class view democracy}

Repertory grid data analysis and the transfer of that data into a semantic differential will be illustrated by an extract of a study on Singaporean middle-classes' ${ }^{6}$ view on democracy. As the first step of a multi-level approach, Singapore has been identified as a prototypical outlier in the context of discussions about meanings of democracy. The selection of this case is based on a regression of Lu and Shi (2015), in which they were able to show for non-Western countries that in some cases, especially in China, Vietnam, Thailand and Singapore, the evaluation of their own country as a democracy differs from that of Freedom House. More current survey data support Lu and Shi's (2015) analyses. Fig. 1 illustrates the current results. Perceived democratic quality is operationalized by the percentage of respondents who give

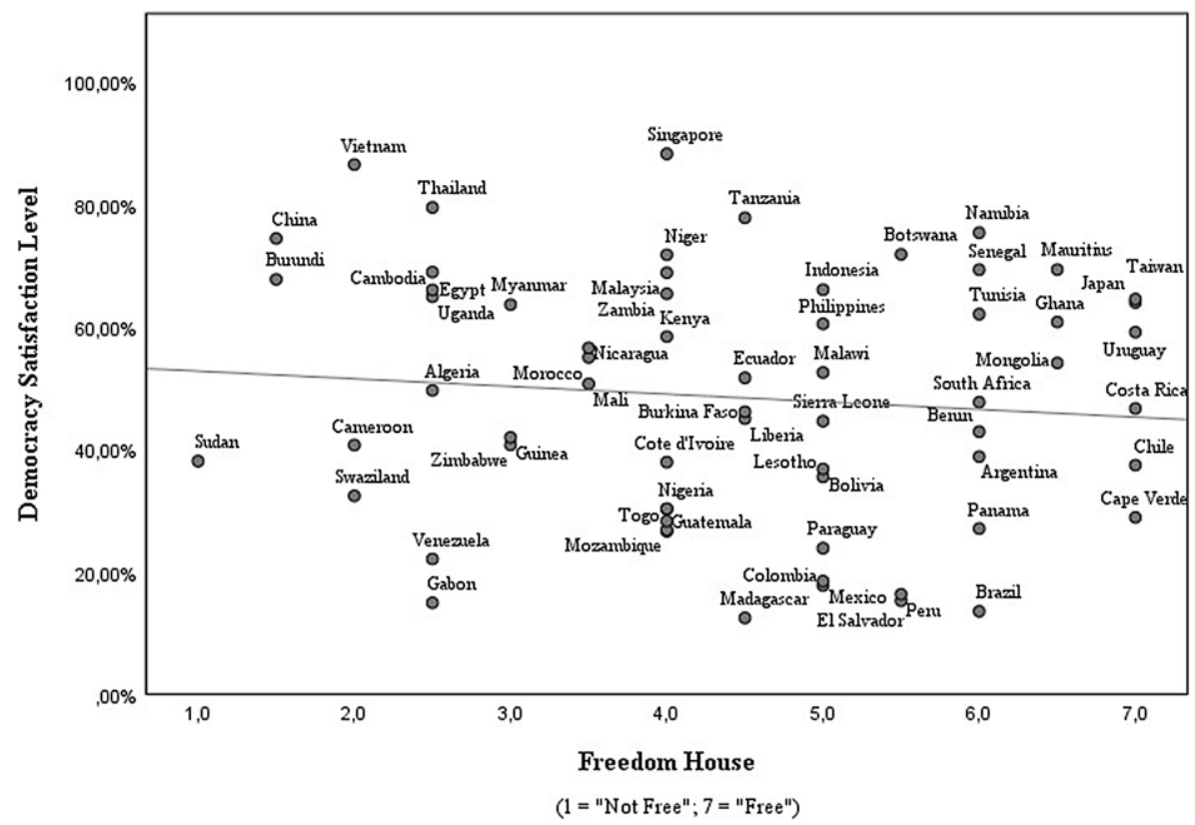

Fig. 1 Perceived democratic quality and Freedom House (Satisfaction level operationalized by questions asking, "how satisfied or dissatisfied are you with the way democracy works in [Country]". Answers "Very satisfied" and "Rather satisfied" (as opposed to "Not very satisfied" and "Not at all satisfied") have been categorized as positive answers indicating satisfaction with democracy). (Source: own calculations with data from Freedom in the World (Freedom House 2017); African (Round 6 in 2016); Asian (Wave 4 from 2014-2016; data analyzed in this article were collected by the Asian Barometer Project (2013-2016), which was co-directed by Professors $\mathrm{Fu} \mathrm{Hu}$ and Yun-han $\mathrm{Chu}$ and received major funding support from Taiwan's Ministry of Education, Academia Sinica and National Taiwan University; the Asian Barometer Project Office (www.asianbarometer.org) is solely responsible for the data distribution; the author(s) appreciate the assistance in providing data by the institutes and individuals aforementioned; the views expressed herein are the authors' own); and Latinobarometer (www.latinobarometro.org))

\footnotetext{
6 The classification of the respondents to the middle-class was made in the survey of demographic data at the end of the interviews based on the self-assessment of the respondents themselves.
} 
positive answers to the question "how satisfied or dissatisfied are you with the way democracy works in [Country]". This is contrasted with the Freedom House Score as an objective evaluation of the quality of democracy.

In defining outliers as countries with a Freedom House score of 4 ("Partly Free") and below combined with a democracy satisfaction level of $60 \%$ and above, Zambia, Malaysia, Niger, Singapore, Myanmar, Uganda, Egypt, Cambodia, Thailand, Vietnam, Burundi and China meet these conditions. ${ }^{7}$ Singapore receives special interest in this group of outliers because its conditions for democratization according to the early modernization theory (Lipset 1959) would be extremely advantageous compared to the other cases. However, Freedom House (2017) characterizes the political system of Singapore as only partly free (4).

The middle-class plays a particularly important role in early modernization theory because a causal relationship between economic development and political change is assumed and it is argued that in the long run, a collapse of authoritarian rule is inevitable because economic growth in the middle-class would ultimately mean the development of a vibrant civil society (Hewison and Rodan 2014). Singapore is a pertinent illustration that modernization theory, with its causal sequence of capitalism, a liberalizing middle-class and, finally, liberal democracy, seems to be outdated (Thompson 2019). Although it has all the advantageous conditions that, according to early modernization theory, favor the development of democracy, Singapore remains an autocracy (Croissant 2016). Bellin (2000) developed an alternative theoretical framework to explain, in the context of late development, a different support behavior for democracy in the different social classes than that which early modernization theory had derived from the experiences in Western Europe. The fundamental insight that can be derived from Bellin's (2000) considerations is that capital and labor are to be understood as contingent democrats because they are first and foremost consistently defending their material interests. Where state elites are skeptical about democracy, private economic actors will also hold back in order not to jeopardize their interests (Robinson 2014). Consequently, the middle-class cannot be described as permanently progressive and democracy-supporting or permanently conservative. How the Singaporean middle-class views democracy will be therefore in the focus of the repertory grid analysis, outlined in this chapter.

\subsection{Preparatory step for the repertory grid technique: the selection of appropriate elements}

In the repertory grid methodology, the elements have to be adequate representations of the topic (things, people, situations, e.g. (Jankowicz 2004)). As in the current study on meanings of democracy, the developed set of elements, as a first step and basis of the repertory grid interview, consists of 15 theoretical representations

\footnotetext{
7 Including the outliers in correlation analyses results in a non-significant relationship between perceived democratic quality and Freedom House (Spearman's rho $=-0.09, \mathrm{p}=0.46, \mathrm{~N}=64$ ). Excluding the outliers yields a slightly significant correlation of Spearman's rho $=0.28(\mathrm{p}=0.05, \mathrm{~N}=52)$ with a slightly medium effect size (Cohen 1992), which validates the classification as outliers.
} 
of democracy research, namely "democracy", "elections", "civil rights", "equal rights", "most appropriate form of government", "most legitimate rule", "income equality", "redistribution", "unemployment benefit", "military", "religious leaders", "obedience", "security", "prosperity", as well as the referential element "your own country". The empirical foundation of the elements selection is oriented on the World Value Survey (wave 6) items on the understanding of democracy, plus the normative element "most legitimate rule", the realistic element "most appropriate form of government", "your own country" to evaluate the Singaporean political system within the meaning of democracy and "security" and "prosperity" to include two elements of output legitimacy, which could be an option to legitimize nondemocratic alternatives. "Elections" $(70.9 \%)$, "equal rights" $(66.8 \%)$ and "civil rights" $(57.9 \%)$ stand for the liberal core of democracy, while "army" (20.2\%) and "religious leaders" (17.4\%) represent non-democratic elements. Social aspects or social populist aspects of democracy are covered by "unemployment benefit" $(52.1 \%)$, "redistribution" (42.1\%), and "income equality" (36.5\%). And "obedience" (37\%) covers a more populist authoritarian element of meanings of democracy (Schubert 2016, p. 292 ff.).

\subsection{Repertory grid analysis by the spatial arrangement of elements and constructs}

The above-mentioned repertory grid interview procedure results in a data set which is the starting point of quantitative analyses through cluster and principal components analysis. The principal component analysis of a multiple repertory grid provides two basic pieces of information about how a group of people thinks and feels about a given topic. The very first information is the spatial arrangement of each element. The further away the elements are from each other, the more differently they are perceived. The closer they are to each other, the more similarly they are perceived. In the present study, the spatial distance of the elements was determined by their factor values for the identified principal components. The second information of a multiple repertory grid is the spatial arrangement of the constructs in comparison to the spatial arrangements of the elements. This was determined in the present study by the respective factor loadings of a construct on each principal component. The closer a construct is to an element (identified by factor values of elements compared to factor loadings of constructs), the more characteristic that construct is for that element.

\footnotetext{
8 Democracy as a topic of the study itself is at the same time part of the elements, because the repertory grid methodology has not been used systematically to address this issue so far, so the authors could not rely on earlier findings as to whether it works at all. Therefore, the authors tried to make it as easy as possible for respondents to talk about their emotional and cognitive associations with democracy. By using the topic as an element, the respondents were forced to operate explicitly with the topic at each individual rating session. In this way, the authors wanted to activate the relevant association networks of the respondents and thus keep them easily accessible. In social psychology this process is called priming.

9 Percentages illustrate the agreement of World Value Survey wave 6-respondents that these elements characterize democracy (Schubert 2016, p. 293 f.).
} 
The $\mathrm{R}$ program environment ( $\mathrm{R}$ Core Team 2018) and the software congrid ${ }^{\circledR}$ (permitto $\mathrm{GmbH} 2019$ ) have been used for statistical analyses. As a result of the interviews, 17 participants delivered a total of 190 constructs. Three main components (PC) were extracted, which explains $87 \%$ of the variance in the total (divided into 47, 30 and 10\% on PC 1, PC 2 and PC 3). Due to the combination of qualitative and quantitative methodology, the sole use of quantitative standards to evaluate the results of the analysis would not be appropriate in the authors' view. Additional qualitative information should be considered when interpreting the spatial arrangement of elements and constructs. For this purpose, the congrid ${ }^{\circledR}$ software provides a graphical overview of the described spatial structure of the multiple repertory grid, as shown in Fig. $2^{10}$. The underlying Euclidean distances are documented in Fig. 3.

Combining spatial arrangement and Euclidean distances, the data show that there is a core meaning of democracy that consists of elections as an integral part of the concept of democracy. ${ }^{11}$ Both democracy and elections are seen as the most ap-

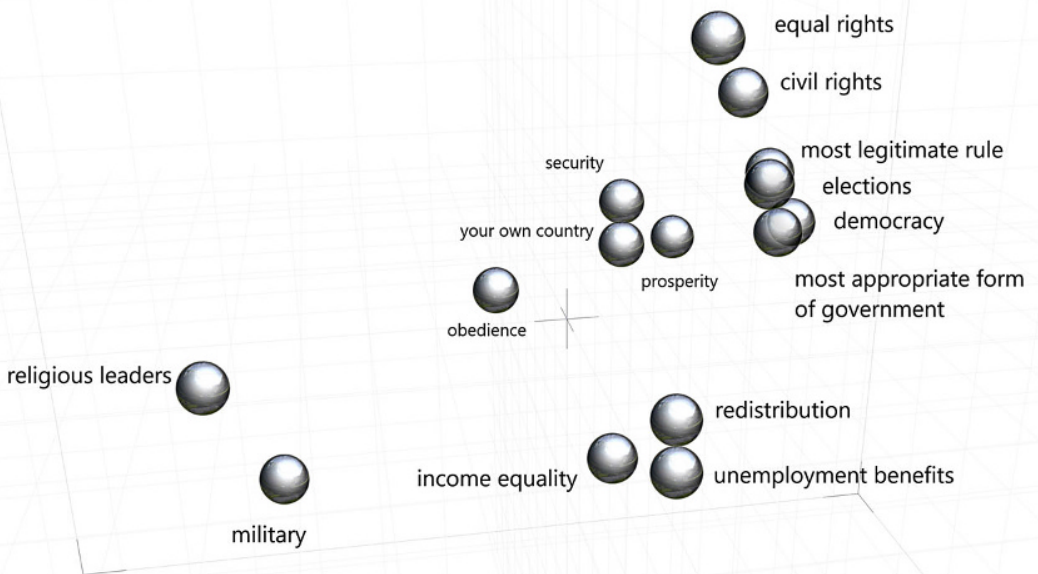

Fig. 2 Spatial arrangement of elements. (Source: Own data)

\footnotetext{
10 The spatial arrangement of elements and constructs is most informative when it is visualized by interactive software. Further examples of visualization can be found in the online appendix. In comparison with Fig. 2 and Fig. 4 (online Supplement) shows another possible perspective within the three-dimensional visualization of the grid. In Fig. 5 (online Supplement), in addition to the elements (Fig. 2 and Fig. 4 [online Supplement]), the constructs developed during the interviews were also made visible.

11 Euclidean distances alone are not a solid basis for our interpretation. In addition, the spatial arrangement of groups of elements was taken into account. Fig. 2 shows that the three elements mentioned above,
} 


\begin{tabular}{|c|c|c|c|c|c|c|c|c|c|c|c|c|c|c|c|}
\hline & 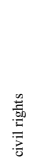 & $\begin{array}{l}\text { 总 } \\
\text { o. } \\
\text { 言 }\end{array}$ & $\begin{array}{l}\text { 总 } \\
\frac{\mathrm{z}}{\mathrm{g}}\end{array}$ & 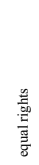 & 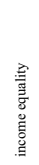 & 胥 & 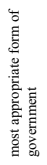 & 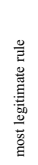 & 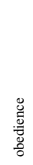 & $\begin{array}{l}\text { 育 } \\
\text { 产 } \\
\text { o. }\end{array}$ & 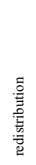 & 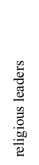 & 言 & 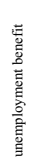 & 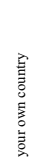 \\
\hline civil rights & & 427 & 408 & 273 & 572 & 773 & 382 & 345 & 612 & 495 & 507 & 789 & 495 & 528 & 490 \\
\hline democracy & & & 364 & 472 & 644 & 765 & 395 & 406 & 621 & 487 & 576 & 775 & 526 & 579 & 479 \\
\hline elections & & & & 428 & 622 & 786 & 403 & 372 & 609 & 474 & 567 & 801 & 529 & 604 & 488 \\
\hline equal rights & & & & & 566 & 770 & 426 & 370 & 615 & 514 & 517 & 768 & 517 & 534 & 505 \\
\hline income equality & & & & & & 634 & 565 & 560 & 562 & 596 & 406 & 676 & 556 & 361 & 532 \\
\hline military & & & & & & & 786 & 784 & 541 & 688 & 644 & 355 & 657 & 629 & 633 \\
\hline most appropriate form of government & & & & & & & & 332 & 598 & 441 & 508 & 798 & 467 & 526 & 426 \\
\hline most legitimate rule & & & & & & & & & 582 & 488 & 476 & 784 & 469 & 509 & 455 \\
\hline obedience & & & & & & & & & & 562 & 550 & 573 & 500 & 579 & 445 \\
\hline prosperity & & & & & & & & & & & 553 & 705 & 463 & 569 & 414 \\
\hline redistribution & & & & & & & & & & & & 675 & 515 & 311 & 471 \\
\hline religious leaders & & & & & & & & & & & & & 695 & 668 & 635 \\
\hline security & & & & & & & & & & & & & & 522 & 427 \\
\hline unemployment benefit & & & & & & & & & & & & & & & 513 \\
\hline your own country & & & & & & & & & & & & & & & \\
\hline
\end{tabular}

Fig. 3 Euclidean distances between elements (dark shading represents large relative Euclidean distance). (Source: Own Data)

propriate form of government (democracy) and the most legitimate rule (elections). Singapore's political system is identified to have two output elements, prosperity and security, both of which are not perceived as democratic. The two social-democratic elements of redistribution and unemployment benefits do not belong to the respondents' meaning of democracy. Definitely not part of the respondents' concept of democracy and with the greatest distance to democracy are the military and religious leaders as undemocratic elements, plus obedience and income equality as social or authoritarian populist elements. ${ }^{12}$

Less obvious is the question of whether civil rights and equal rights belong to this core of democracy. A first possible interpretation is that there is an inner core of democracy consisting of elections and an extended core that includes civil rights, equality and one's own country (Singapore). There is an additional group of elements consisting of prosperity and security. This interpretation would foster the assumption of a liberal core of democracy (elections, civil rights, equal rights). The second possible interpretation could be that there is one group of elements consisting of civil rights and equal rights and another group consisting of the own country (Singapore), prosperity and security. This interpretation would support the argument that there is only a minimalist meaning of democracy, consisting of elections, which does not necessarily include civil rights and equal rights. Typically, the finding that one element is in the middle of a repertory grid means that respondents are indifferent

although similar in distance, lie in different directions (indicated by the non-visualized vector from the origin point to the element). In repertory grid, this is an indicator of semantic dissimilarity. Taken together, it should be noted that repertory grid is a mixture of qualitative and quantitative methods. Drawing the line between these two is clearly a matter of clinical reasoning and interpretation.

12 The categorization of the elements into social democratic, undemocratic and authoritarian populist are based on Schubert (2016, p. $292 \mathrm{ff}$.). 
to that element ${ }^{13}$ and attention should be focused on the qualitative analysis of the repertory grid.

Cluster analysis of all elements identified five first-order clusters, which show similarities in the ways of having been evaluated on the constructs by participants. Analyzing the five clusters (I democracy and election, II civil rights and equal rights, III most appropriate form of government and most legitimate rule, IV unemployment benefit and redistribution, $V$ military and religious leaders) construct clouds allow a better understanding of how the respondents described the elements and their shared characteristics (Appendix, Table 4). Construct clouds is a congrid ${ }^{\circledR}$ analysis feature that investigates distances between single constructs and groups of elements. Thus, the democracy-election-cluster (I) is characterized as caring, fair(ness), progress(ive) and free (dom $)^{14}$. Besides the characterization of this cluster as free and fair, there are also descriptions that are closer to communitarian and communityoriented ideas of government than to liberal ideas of democracy. Communitarians regard the self as embedded in the community and not as an independent actor. They argue that individuals who are well integrated into communities are better able to think and act responsibly than isolated individuals. Communitarianism emphasizes the responsibility that people have for their families, relatives, communities and societies-beyond the universal rights that each individual has. This also means taking care of one's friends and family, cooperating with neighbors, striving for social justice, and so on. In the Asian tradition, communitarianism argues that individual rights and political freedoms must be curtailed to maintain social harmony. There is thus a contradiction here that seems to lead to polarization or ambiguity among the respondents (Etzioni 2010). The civil and equal rights-cluster (II) is described as successful, chosen, fair and free. This means that both clusters are perceived as being free and fair, although the most applicable characterization for the civil and equal rights-cluster is successful and caring for the democracy-elections-cluster. Thus, with the description of cluster II as free and fair and its simultaneous perception as successful and chosen, there seems to be a liberal meaning of democracy on the one hand and a pragmatic view of good governance legitimized by communitarianism on the other.

The cluster most appropriate form of government and the most legitimate rule (III) is perceived as empower(ing)ment, caring and common. The cluster democracy and elections (I) and the cluster most appropriate form of government and most legitimate rule (III) are perceived as having very similar characteristics. This similarity in the perception of the respondents is not only visible in the cluster analysis but could be read in the spatial arrangements of the elements (Fig. 2). What they share in particular is described as caring. Even though freedom and fairness seem to have a value relevant to democracy alongside pragmatic considerations, the latter dominates with the perception of the most appropriate and most legitimate rule as

\footnotetext{
13 These indifferences have to be seen in the context of the observed response behavior during the Interviews. Respondents relatively easily found opposing constructs, but in evaluating the elements within those construct scales they tended to more moderate evaluations of the elements.

14 Italics stands for original formulations in the interviews. Non-italic script stands for grammatical and, with regard to the semantic differential, also methodical modifications of the authors.
} 
empowering, caring and common. This leads to a confirmation of the previous interpretation of a rather minimalist meaning of democracy in the Singaporean middle-class, which is largely defined by elections. On the basis of a larger database it would be interesting to examine whether the attribute caring could be seen in the as successful, educated, ag agree(able)ment, just, stab(le)ility, essential, pragmatic, patriarchal and contractual. context of the Confucian state tradition in the sense of a father-son relationship ${ }^{15}$, and thus refer to the Asian values debate, or rather whether it stems from the Singaporean ideology of pragmatism.

Cluster IV, redistribution and unemployment benefits are perceived mainly as balance(ed), secure, adaptable and concessionary. And cluster V military and religious leaders are most frequently described as restricting and subaltern. Finally, Singapore is perceived mainly as successful, educated, agree(able)ment, just, stab(le)ility, essential, pragmatic, patriarchal and contractual. Singapore shares the attributes of success with the element of prosperity and educated, just and agreeing with the element security.

These qualitative interpretations of the quantitative results of the cluster analysis support the interpretation of a minimal meaning of democracy, which may, but does not necessarily have to, include civil and equal rights. Singapore seems to belong to the group of security and prosperity.

\subsection{Repertory grid analysis by construct loading patterns on principal components}

The second of the two basic pieces of information provided by a multiple repertory grid about the thoughts and feelings of a group of people on a particular topic are the common patterns behind the individual construct structures. For this reason, the multiple grid's data structure can be ordered by elements as lines and constructs as columns. In a first step, this data structure is analyzed by employing principal components analysis, which results in the factor structure shown in Table 2 (reduced to the five constructs with the highest loadings on each component).

These principal components could be broadly interpreted as the structure of Easton's (1965) political system model, which consists of inputs by demands of and support by the people, the political system with its respective institutions and processes and the outputs in the form of decisions and actions. The principal component PC 1 reflects the input dimension of legitimacy underlining aspects of freedom and liberty. PC 2 is similar to the throughput or governmental dimension with its in-

\footnotetext{
15 In the sense of MacFarquar (1980) and Chua (1995), Confucianism is to be understood as a "philosophical justification of government by benevolent bureaucracy under a virtuous ruler." This benevolent rule of a leader is "reciprocated by the loyalty and obedience of his subjects." Benevolence ensures harmony and obedience within stratified and unequal social relations. "(S)imilar harmonious inequality exists in the relationships between father and son, husband and wife, older and younger." Family members are harmoniously defined in their respective hierarchical relationships. These family feelings and the associated behaviors are interchangeable with national feelings (Chua 1995, p. 151).
} 
Table 2 Construct loadings and principal components. (Source: Own data)

\begin{tabular}{lllll}
\hline Construct pole & Loading PC 1 & Loading PC 2 & Loading PC 3 & Antipole \\
\hline Authority & 0.63 & - & - & Freedom \\
Authoritarian & 0.57 & - & - & Elected \\
Authoritative & 0.45 & - & - & Fairness \\
Efficient & -0.40 & - & - & Authority \\
Openness & -0.42 & - & - & Unquestionability \\
Egalitarianism & - & 0.95 & - & Hierarchy \\
Ideals-oriented & - & 0.79 & - & Physical \\
Elected & - & 0.71 & - & Authoritarian \\
Non-political & - & 0.69 & - & Political \\
Redistributive & - & 0.68 & - & Prosperous \\
Exclusive & - & - & 0.97 & Common \\
Safe & - & - & 0.92 & Well-off \\
Prosperous & - & - & 0.85 & Redistributive \\
Income inequality & - & - & 0.85 & Fair \\
Educated & - & - & 0.77 & Poor morals \\
\hline
\end{tabular}

Constructs with loadings amounting lower 0.40 are omitted

stitutions and procedures. And PC 3 is output focused on social benefits and other outcomes ${ }^{16}$.

Nevertheless, the aim of this first study has not been to determine the final dimensions of the meaning of democracy in Singapore. The present data set is restricted to Singaporean middle-class and can deliver first hints only due to its small- $N$. These first ideas have to be tested in a larger study. The identified principal components of the repertory grid therefore will be the basis for the conceptual pairs of a subsequent semantic differential, which allows for large- $N$ studies.

\section{Semantic differential}

The semantic differential method goes back to Charles Osgood (1952). The method has been developed in psychology to identify people's associations with certain terms, facts, or plans.

It does not use any direct questions like "What do you think about ...?". Instead, people are asked indirectly by giving them the opportunity to tell how strong they associate, e.g. the term "democracy" (or another test unit) with certain characteristics. They are given a number of pairs of characteristics such as "elected—announced" or "open-close" and can specify whether they associate "democracy" with "elected"

\footnotetext{
16 Since this is an interpretation of the PCA dimensions, the single dimensions naturally include issues that do not fit $100 \%$ into the three dimensions of Easton's legitimacy model. For example, there seem to be poles that are significant for several dimensions, such as fair, prosperous or redistributive. Notwithstanding these isolated deviations from Easton's model, the overall similarity of the PCA dimensions to the input, throughput and output dimensions is astonishing.
} 
or "announced" and to what extent they do so (Hofstätter 1986). Similar to the repertory grid, semantic differential analysis evaluates patterns of evaluation based on opposing conceptual pairs. The pairs of terms frequently used in the semantic differential usually stem from the academic expertise of the researcher or from predefined sets of semantic lists (Osgood et al. 1957; Rosenberg and Navarro 2018) and are thus top-down generated.

In the present case, the authors applied the identified constructs, which proved to be the strongest in the repertory grid analysis, as pairs of terms. The term pairs of the outlined research design are thus generated bottom-up. In a first step, the construct strength was evaluated by ranking the constructs along with their loading on the main components of the multiple repertory grid. In a second step, the resulting three groups of constructs were then used as a content analytical categorization framework for all other constructs. In accordance with the recommendations of Jankowicz (2004), all items were compared with the initial three categories and assigned to the appropriate category. If no such matching category existed, a new one has been created. This procedure continued until all items had been assigned. In a third and final step, the qualitatively determined category structure has been compared with clusters of quantitatively correlating constructs in order to extract all given information.

At this stage of the research, the authors consider it too early to report on the specific categories that have been found in the described approach. These categories should be further tested in future Large- $N$ analyses. With this in mind, the authors decided from an economic point of view to create a semantic differential with a maximum number of 50 items. ${ }^{17}$ The application in representative large samples will allow researchers to test the category system by means of a confirmatory factor analysis. Table 3 shows selected examples of constructs that have been slightly reworded for the sake of linguistic clarity. The participants of the semantic differential questionnaire will be asked to evaluate their concepts of democracy (which were used as elements in the repertory grid analysis) between the two poles of constructs.

Through this study design large- $N$ data can be obtained, which nonetheless focuses on the most relevant bottom-up perceptions of democracy. Therefore, the integration of repertory grid and semantic differential methodologies can give an efficient combination of qualitatively deep insights, which are verified by common large-scale data analysis methods applied to large samples, which reduce measurement error biases.

\footnotetext{
17 At this point, the authors would like to thank an anonymous reviewer of the manuscript for valuable input regarding the content analysis of the Repertory Grid constructs. Although the 190 constructs produced by 17 participants provide a good basis for differentiating the experience patterns with regard to the topic of democracy, the authors decided to enlarge the Repertory Grid sample before carrying out further largescale investigations to derive a semantic differential.
} 
Table 3 Selected examples of conceptual pairs. (Source: Own data)

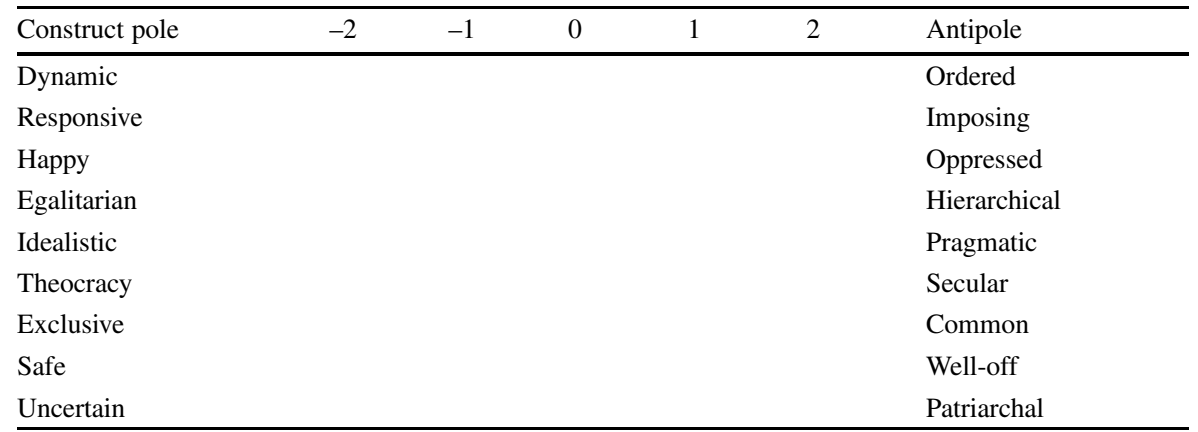

Conceptual pairs for a semantic differential concerning the meaning of democracy in Singapore as a result of the multiple repertory grid analyses

\section{Conclusion}

The starting point of this article was the recognition of the contentious nature of the concept of democracy. From this, the present argumentation derives, firstly, the rejection of the idea of a universally homogeneous understanding of democracy, which, by its transfer to the long-established method of asking for support for democracy via surveys, has led to the artificial result of overwhelming worldwide support for democracy. Both considerations, therefore, lead secondly to a need for alternative methodological approaches which, beyond the question of support for normative (Western) connotations of democracy (top-down), offer possibilities to measure support and above all meanings of democracy by supplementing deductive approaches with inductive approaches. ${ }^{18}$ In this sense, the article proposes a mixedmethod and a multi-level approach consisting of the repertory grid method and the semantic differential method as methodological alternatives. The combination of these two methods makes it possible to grasp the semantic depth of the concept of democracy and to collect extensive data on the respective cultural context. Taken together, this combined approach reduces the limitations caused by cultural and linguistic equivalence, as well as the phenomena of lip service and social desirability, while at the same time allowing representativeness and generalization.

To illustrate the methodological possibilities of the two methods of differentiation presented here, this article presents some results of repertory grid interviews conducted in Singapore in order to assess the meaning of democracy for the Singaporean middle-class. The most important results on this point are, first of all, a confirmation of the debates on democracy beyond the West (Schubert 2012, 2016), since even in the middle-class of Singapore there seems to dominate a meaning of democracy that shares core elements of the Western liberal meaning of democracy, but is limited to

\footnotetext{
18 Whether the consequence of researching the variety of meanings of democracy ultimately leads to the realization that support for democracy is lower or even higher than previously assumed, cannot be answered with empirical evidence alone. A theoretical and conceptual debate on the components of democracy and its essential core is necessary, which on the one hand takes into account the diversity of meanings of democracy and on the other hand does not conceptually overstretch the concept of democracy and render it meaningless.
} 
a minimum definition that includes only elections. Civil and equal rights seem to be part of the concept of democracy only in the broader sense. Secondly, military and religious leaders are definitely not considered part of the concept of democracy. Social democratic aspects also do not correspond to the democratic perceptions of the Singaporean middle-class. ${ }^{19}$ However, as discussed in the article, the interpretation of the data beyond the two extremes of democracy and anti-democratic elements is not explicitly possible, since the respondents are generally rather indifferent to democracy, as already discussed in previous research (Schubert 2012). With the help of the spatial arrangements of the elements, a meaning of democracy could be depicted that shows similarities and differences to the Western, liberal meaning. The actual meaning, however, which lies behind the similarities and differences, is only revealed by the qualitative data of the interviews. These data could be obtained because the repertory grid works with the interviewee's own words and the interviewees carry out their own evaluation within their own evaluation scales. This subjective evaluation eliminates the effects of linguistic and cultural equivalence within the interview and even makes it possible to understand the different cultural and linguistic meanings of words and evaluation systems during the analysis. In the methodological discussion on alternative methodological approaches to investigate global meanings of democracy, the repertory grid is a promising option of the inductive bottom-up approach. In order to strengthen this inductive character of the repertory grid method in future research projects, the selection of elements at the beginning of the interview process probably could also be bottom-up, rather than deriving the elements top-down from the existing research. One possibility pointing in this direction would be, for example, focus group interviews, which in this way develop elements of democracy together with the interview partners (Jankowicz 2004). One challenge remains the comparability of interviews between different interview groups and countries.

To achieve representativeness and thus generalizable results, the authors argue for a multi-level approach. By analyzing the main components of the data structure of the repertory grid, the results can be transferred to the semantic differential method, which, due to the quantitative nature of this method, would then enable a large number of interviews to be carried out. The advantage of this multi-level design is that the construct poles of the semantic differential are based on the repertory grid interview's own constructs and are thus defined bottom-up instead of top-down. In this next step, it will be possible to analyze how Singaporeans see democracy and compare the meanings of democracy between different groups in Singaporean society.

Funding Open Access funding enabled and organized by Projekt DEAL.

Open Access This article is licensed under a Creative Commons Attribution 4.0 International License, which permits use, sharing, adaptation, distribution and reproduction in any medium or format, as long as you give appropriate credit to the original author(s) and the source, provide a link to the Creative Commons licence, and indicate if changes were made. The images or other third party material in this article are included in the article's Creative Commons licence, unless indicated otherwise in a credit line to the

19 Whether this is a class specific view of democracy or whether these findings apply to Singaporean society in its entirety can only be decided conclusively with representative data. 
material. If material is not included in the article's Creative Commons licence and your intended use is not permitted by statutory regulation or exceeds the permitted use, you will need to obtain permission directly from the copyright holder. To view a copy of this licence, visit http://creativecommons.org/licenses/by/4. $0 \%$ 


\section{Appendix}

Table 4 Element cluster and constructs. (Source: Own Data)

First order Construct cloud
cluster

"Democracy",

"Elections" offfairagreementtrustfreedomequalpowerempowermentliberalopenstablechosenAcceptancedesired outcomehoperiskwexcommonfairness

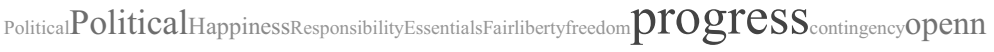
esStransparencyuncontrolleddynamism Freedom Complete

"Civil rights", libertySelfish veFreeResponsible

"Equal rights",

freedom of choicefairagreementformula basedDemocratic and

fairauthorityfreedomequalempowermentliberalstableeducated $\mathbf{c h O S E}$ Acceptancecommonfairnessideals- $_{\text {- }}$ orientedwelfareequalityactivistunrestrictivepredictablefairNon-

PoliticalPoliticalFairnessHappinessResponsibilityEssentials FairJustlibertyfreedomequityprogressself fulfilmentcontingencyopennesstransparencyegalitarianismconcernFreedomComplete

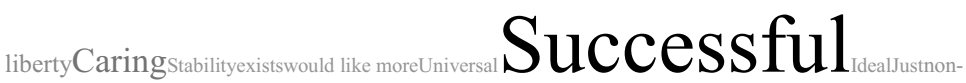

discriminationoutcomesoptimisticElectedRedistributive FreeresponsibleJust

"Most appropriate form of government", "most legitimate rule" freefairresponsiveequalsurvivalfreedom of choicewell offfairagreementformula basedtrustDemocratic and

"Redistribution", "Unemployment benefit" empowerment

averseCOMmOnideals-orientedentrustedactivistunrestrictivepredictablefairNon-

PoliticalPoliticalHappinessResponsibilityEssentialsutilitylibertycontingencyopennesstransparencyuncontrolleddynamisme galitarianismFreedomComplete liberty Caring StabilityConsensuswould like

moreUniversalSuccessfulidealPragmaticJustsecularnon-

discriminationelectedoptimisticElectedRedistributiveFreeResponsibleSecularOpressive

Successfulfreefairresponsiveequalsurvivalbackupforced upondishonestyDemocratic and fairSocially

ResponsibleSupportCOnCeSS1Onary partialgenerousityfairopenAcceptancelazyrisk-

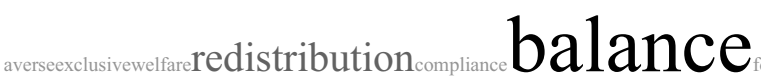

Adaptable EntitlementutilitymoralityequitydependencyauthoritativeregulationCaringNot the same for allidealsecularRedistributive SeCU1 PopulistResponsible

"Military", "Religious leaders"

\section{restricting}

rruptiontotalitarianismConfrontat

ionalexclusiveauthoritativeauthoritariandirectivecompliancerestrictiveFairnessEntitlementNot a

needBiasForcedauthoritativeUnquestionabilityregulationorderForcefulOppressionAuthoritarianFailed

governmentdistrustincapablepessimisticAuthoritarianoppressed Subaltern

This table summarizes first order element clusters as well as most associated constructs (the larger the font in the construct cloud, the nearer the construct is to the elements in the cluster) 


\section{References}

Bellin, Eva. 2000. Contingent democrats. Industrialists, labor, and democratization in late-developing countries. World Politics 52:175-205.

Bratton, Michael. 2010. Anchoring the "D-Word" in Africa. Journal of Democracy 21(4):106-113.

Canache, Damarys, Jeffery J. Mondak, and Mitchell A. Seligson. 2001. Meaning and measurement in cross-national research on satisfaction with democracy. Public Opinion Quarterly 65(4):506-528.

Cho, Youngho. 2015. How well are global citizenries informed about democracy? Ascertaining the breadth and distribution of their democratic enlightment and its sources. Political Studies 63:240-258.

Chu, Yun, and Min Huang. 2010. Solving an Asian puzzle. Journal of Democracy 21(4):114-130.

Chua, Beng-Huat. 1995. Communitarian ideology and democracy in Singapore. New York: Routledge.

Cohen, Jacob. 1992. A power primer. Psychological Bulletin 112(1):155-159.

Collier, David, Fernando Daniel Hidalgo, and Andra Olivia Maciuceanu. 2006. Essentially contested concepts: Debates and applications. Journal of Political Ideology 11(3):211-246.

Croissant, Aurel. 2016. Singapur. In Die politischen Systeme Südostasien, ed. Aurel Croissant, 439-483. Wiesbaden: Springer VS.

Dallmayr, Fred. 1997. Introduction: Toward a Comparative Political Theory. The Review of Politics 9(13): 421-428.

Dallmayr, Fred. 2010. Comparative political theory: an introduction. New York: Palgrave Macmillan.

Dalton, Russell J., C. Shin Doh, and Willy Jou. 2008. How people understand democracy. In How people view democracy, ed. Larry Diamond, Marc F. Plattner, 1-15. Baltimore: The Johns Hopkins University Press.

Diamond, Larry, and Marc F. Plattner. 2008. How people view democracy. Baltimore: The Johns Hopkins University Press.

Easton, David. 1965. A Systems Analysis of Political Life. New York: John Wiley.

Etzioni, Amitai. 2010. Communitarianism. In International encyclopedia of civil society, ed. Helmut K. Anheier, Stefan Toepler. Berlin, Heidelberg, New York: Springer. https://doi.org/10.1007/9780-387-93996-4_66.

Freedom House. 2017. Freedom in the World 2017, https://freedomhouse.org/sites/default/files/FH_FIW_ 2017_Report_Final.pdf. Accessed 3.10.2020.

Gagnon, Jean-Paul. 2018. 2,234 descriptions of democracy. An update to democracy's ontological pluralism. Democratic Theory 5(1):92-113.

Harkness, Janet A., Michael Braun, Brad Edwards, Timothy P. Johnson, Lars Lyberg, Peter P. Mohler, Beth-Ellen Pennell, and Tom W. Smith. 2010. Survey methods in multinational, multiregional, and multicultural contexts. Wiley series in survey methodology. Hoboken: John Wiley \& Sons.

Hewison, Kevin, and Garry Rodan. 2014. The left and the rise of bourgeoise opposition. In Routledge handbook of southeast asian politics, ed. Richard Robinson, 25-39. New York: Routledge.

Hofstätter, Peter Robert. 1986. Gruppendynamik: Kritik der Massenpsychologie. Reinbek: Rowohlt.

Jankowicz, Devi. 2004. The easy guide to repertory grids. Chichester: John Wiley \& Sons Ltd.

Jarzabkowski, Paula, Wendy K. Smith, Ann Langley, and Marianne W. Lewis. 2017. The Oxford handbook of organizational paradox. Oxford: Oxford University Press.

Kaulartz, Markus, and Jörn Heckmann. 2014. Comparing interactive online and face-to-face repertory grid interviews in terms of construct quality and practicability. 12th Biennial Conference of the European Personal Construct Association (EPCA), Brno, Czech Republic. Talk.

Kelly, George Alexander. 1955. The psychology of personal constructs. New York: Norton.

Lipset, Seymour Martin. 1959. Some social requisites of democracy: economic development and political legitimacy. The American Political Science Review 53(1):69-105.

Lu, Jie, and Tianjian Shi. 2015. The battle of ideas and discourses before democratic transition: Different democratic conceptions in authoritarian China. International Political Science Review 36(1):20-41.

MacFarquar, Roderick. 1980. The post-confucian challenge. The Economist 9:67-72.

Miron-Spektor, Ellen, Amy Ingram, Joshua Keller, Wendy K. Smith, and Marianne W. Lewis. 2018. Microfoundations of organizational paradox: the problem is how we think about the problem. Academy of Management Journal 61(1):26-45.

Moosbrugger, Helfried, and Augustin Kelava. 2008. Testtheorie und Fragebogenkonstruktion: mit 43 Tabellen. Berlin, Heidelberg, New York: Springer.

Osgood, Charles Egerton. 1952. The nature and measurement of meaning. Psychological Bulletin 49(3):197-237.

Osgood, Charles Egerton. 2009. Semantic differential technique in the comparative study of cultures. American Anthropologist 66(3):171-200. 
Osgood, Charles Egerton, George J. Suci, and Percy H. Tannenbaum. 1957. The Measurment of meaning. Urbana, Chicago: University of Illinois Press.

permitto. 2019. congrid. permitto GmbH, Wiesbaden.

Pickel, Gert. 2009. Der Einbezug des Individuums in die Länderanalyse - Umfrageforschung und vergleichende Politikwissenschaft. In Methoden der vergleichenden Politikwissenschaft. Neue Entwicklungen und Anwendungen, ed. Susanne Pickel, Gert Pickel, and Hans-Joachim Lauth, 297-315. Wiesbaden: VS.

R Core Team. 2018. A language and environment for statistical computing. R Foundation for Statistical Computing, Vienna, Austria. https://www.R-project.org/. Accessed 3.11.2020

Robinson, Richard. 2014. Interpreting the politics of Southeast Asia: debates in parallel universes. In Routledge handbook of Southeast Asian politics, ed. Richard Robinson, 5-22. New York: Routledge.

Rosenberg, Benjamin, and Mario A. Navarro. 2018. Semantic differential scaling. In The SAGE encyclopedia of educational research, measurement, and evaluation, ed. Bruce B. Frey, 1504-1507. Thousand Oaks: SAGE.

Rost, Jürgen. 2004. Lehrbuch Testtheorie-Testkonstruktion. Bern: Huber.

Rudolph, Thomas J. 2005. Group attachment and the reduction of value-driven ambivalence. Political Psychology 26(6):905-928.

Sartori, Giovanni. 1997. Demokratietheorie. Darmstadt: Wissenschaftliche Buchgesellschaft.

Schubert, Sophia. 2012. Die globale Konfiguration politischer Kulturen. Eine theoretische und empirische Analyse. Wiesbaden: VS.

Schubert, Sophia. 2016. Inwiefern universal? Zum Demokratiebegriff in der Vergleichenden Demokratieforschung. In Transkulturelle Politische Theorie. Eine Einführung, ed. Sybille de la Rosa, Sophia Schubert, and Hubert Zapf, 285-303. Wiesbaden: Springer VS.

Schubert, Sophia, and Alexander Weiß. 2016. Demokratiekonzeptionen jenseits des Westens: Ein theoretischer Rahmen für ein neues Forschungsfeld. In "Demokratie" jenseits des Westens. Theorien, Diskurse, Einstellungen, ed. Sophia Schubert, Alexander Weiß, 6-34. Baden-Baden: Nomos.

Shcheglova, Marina. 2010. An integrated method to assess consumer motivation in difficult market niches: A case of the premium car segment in Russia. https://depositonce.tu-berlin.de/handle/11303/2685. Accessed 25 Sept 2020.

Thompson, Mark R. 2019. Singapore in the lineage of authoritarian modernity in East Asia. In The limits of authoritarian governance in Singapore's developmental state, ed. Lily Zubaidah Rahim, Michael D. Barr, 29-48. Singapore: Springer Singapore.

van de Vijver, Fons J.R. 2003. Bias and equivalence: cross-cultural perspectives. In Cross-cultural survey methods, ed. Janet A. Harkness, Fons J.R. van de Vijver, and Peter P. Mohler, 143-155. Hoboken: John Wiley \& Sons Inc..

Waldman, David A., Linda L. Putnam, Ella Miron-Spektor, and Donald S. Siegel. 2019. The role of paradox theory in decision making and management research. Organizational Behavior and Human Decision Processes 155:1-6.

Walker, Beverly M., and David A. Winter. 2007. The elaboration of personal construct psychology. Annual Review of Psychology 58(1):453-477. https://doi.org/10.1146/annurev.psych.58.110405.085535.

Welzel, Christian, and Ronald Inglehart. 2008. The role of ordinary people in democratization. In How people view democracy, ed. Larry Diamond, Marc F. Plattner, 16-30. Baltimore: The Johns Hopkins University Press.

Yildiz, Taylan. 2012. Übersetzungspraktiken und die widersprüchliche Logik des Politischen. Eine praxistheoretische Grundlegung der Transformationsforschung. In Nichtwestliches politisches Denken, ed. Holger Zapf, 213-228. Wiesbaden: Springer VS. 